\title{
Working
}

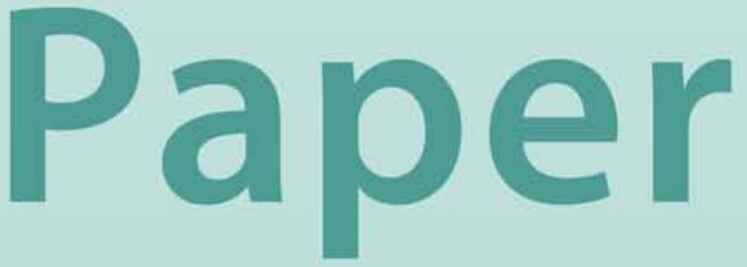




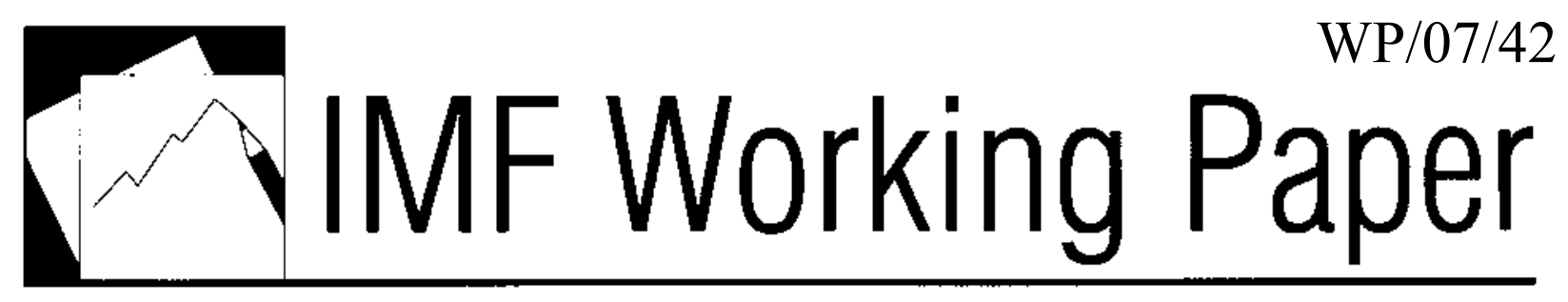

Give Trust a Chance-A Model of Trust in the Context of an IMF-Supported Program

Daouda Sembene 


\title{
IMF Working Paper
}

OED

\section{Give Trust a Chance-A Model of Trust in the Context of an IMF-Supported Program}

\author{
Prepared by Daouda Sembene ${ }^{1}$
}

Authorized for distribution by Laurean Rutayisire

February 2007

\begin{abstract}
This Working Paper should not be reported as representing the views of the IMF. The views expressed in this Working Paper are those of the author(s) and do not necessarily represent those of the IMF or IMF policy. Working Papers describe research in progress by the author(s) and are published to elicit comments and to further debate.

This paper is an attempt to identify the determinants of trust between country authorities and IMF staff in the context of an IMF-supported program. Using an outcomes-based definition of trust, a game-theoretic model is developed to compute the level of trust between the two parties. The results and the analysis of trust-related issues emerging in a program context suggest that trust between country authorities and IMF staff exerts a positive impact on the likelihood of program success through its ability to improve the quality of the design, the efficiency of negotiation, and the effectiveness of implementation of an IMF-supported program. Some initiatives to secure such benefits and enhance trust in staff are proposed.

JEL Classification Numbers:

Keywords: Trust; IMF-supported Program; Program design and implementation; Negotiation Author's E-Mail Address: $\underline{\text { dsembene@imf.org }}$

\footnotetext{
${ }^{1}$ Senior Advisor to the Executive Director, Francophone Africa Constituency, International Monetary Fund (IMF). The views expressed in this paper are my own and do not necessarily represent those of the IMF, its Executive Directors and the countries they represent, or its Management. I am grateful to Rajeev Bhattacharya, Abbas Mirakhor, Mark Plant, Laurean Rutayisire, and Shang-Jin Wei for helpful discussions and useful comments on previous versions of this paper. I am solely responsible for any errors and omissions.
} 
I. Introduction

II. Selective Review of the Literature on Trust

III. Trust in the Context of an IMF-Supported Program..................................................
A. Trust and Program Design.
B. Trust and Program Negotiation...............................................................
C. Trust and Program Implementation

IV. An Outcomes-Based Model of Trust..................................................................

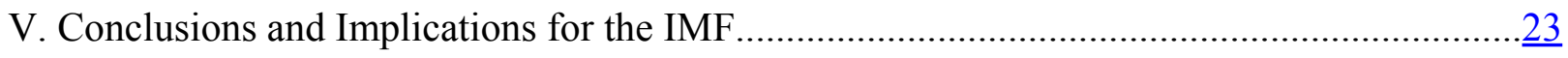

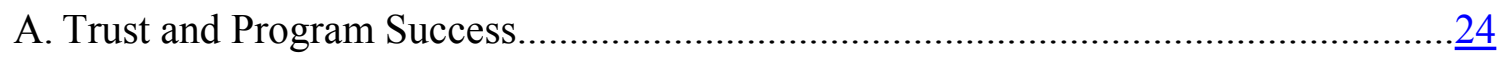

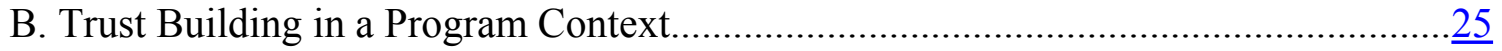

C. Issues for Further Research.........................................................................

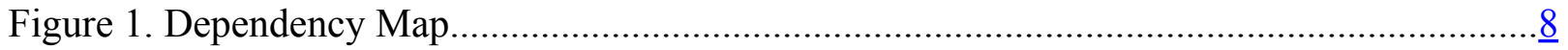

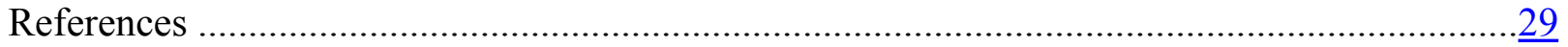


"Trust is an important lubricant of a social system. It is extremely efficient; it saves a lot of trouble to have a fair degree of reliance on other people's word."

Arrow (1974)

\section{INTRODUCTION}

"Virtually every commercial transaction has within itself an element of trust, certainly any transaction conducted over a period of time." This reflection by Arrow (1972) translates a view widely acknowledged in many disciplines including economics that trust matters. Still, the regular transactions that the IMF performs with its member countries since its inception have yet to be scrutinized with a view to better understanding the specific role played by trust. This is at odds with the strong reliance of the institution on members' cooperation, the enduring need to improve the effectiveness of its activities, and the demonstrated importance of trust issues for the efficient functioning of large organizations and institutions. ${ }^{2}$ In addition, the large membership of the IMF would be expected to give more value added to an analysis of the importance of trust in the context of its relations with member countries, particularly those involving IMF's financing. ${ }^{3}$ However, it must be recognized that determining the role of trust in interorganizational relations is challenging, given the difficulties of relating an inherently individual-level concept (trust) to the organizational-level outcome of performance (Zaheer et al., 1998). Not least challenging is to define and formalize trust in the context of IMF activities.

As discussed in the next section, there are numerous definitions of trust across disciplines, many of which can apply to issues of interpersonal and interorganizational trust that emerge in the context of an IMF-supported program. For instance, an IT research group has defined trust as "[the reliance] on something [possibly an organization, an individual, a service, or even a software and hardware] to provide correct information, perform an operation correctly, keep a secret, perform a protocol correctly, [and] not to misuse information or resources. ${ }^{4}$ Although this definition is primarily meant to apply to the notion of trust in information technology, it can characterize, in many aspects, the relations between the IMF and its program countries. ${ }^{5}$ Indeed, the IMF and its personnel rely on program country authorities to (i) provide correct information,

\footnotetext{
${ }^{2}$ Positive implications of trust for economic efficiency and organizational performance have been thoroughly examined in the literature (Ring and Van De Ven, 1992; La Porta, Lopez-de-Silanes, Shleifer, and Vishny, 1997; Zaheer, McEvily, and Perrone, 1998).

${ }^{3} \mathrm{~A}$ loan agreement is often seen in the finance literature as a mark of trust between the lender and the borrower.

${ }^{4}$ http://www.aaaarch.org/dublin/salowey/definition of trust.htm

${ }^{5}$ As such, this concept of trust is different from its legal definition. In the legal terminology, a trust is an entity created to hold assets for the benefit of certain persons or entities, with the trustee managing the trust and the trustors being the founding persons of the trust.
} 
(ii) design sound economic, monetary, and structural policies, (iii) implement the IMFsupported program as presented in the letter of intent, and (iv) not to misuse available resources, particularly IMF resources. In turn, program country authorities expect the IMF and its personnel, as their confidential adviser, to keep secret and not to mishandle some information that they made available to the institution.

This paper attempts to model the level and importance of interpersonal trust between the authorities and the IMF staff in the outcome of IMF program engagement, given that the closest and most frequent interactions between the IMF and its member countries are maintained between these two parties. Trust is defined as an expectancy of positive or nonnegative outcomes from which IMF staff and country authorities can benefit based on each other's expected action. Indeed, to the extent that trust can be conceptually placed in an individual as well as a group of individuals, this definition can apply to working relationships between IMF staff and the authorities in the context of an IMF-supported program.

Since there is virtually no prior work on this topic, the modeling framework developed in this paper is a preliminary step to capture the quantitative importance of trust for sound design, efficient negotiation, and effective implementation of IMF-supported programs. In order to conceptualize the notion of trust in a program context, this paper adapts an outcomes-based model developed by Bhattacharya, Devinney, and Pillutla (1998) to the relationships between IMF staff and country authorities in the context of an IMF-supported program. It describes a game-theoretic situation where the players - IMF's staff and the authorities - move sequentially. During the process of program design and negotiation, IMF staff provides its policy advice. In the subsequent stage of program implementation, the authorities decide whether or not to implement this advice. A key innovation in this paper is that it takes into account the possibility of staff and the authorities having different perceptions of the outcomes of IMF program engagement. This appears to be a major step in accounting for the difficulties involved in the measurement of actual program outcomes as well as the uncertainty associated with the relationship between staff's advice and the actual outcomes of program implementation.

The paper gives a clear sense of the key role played by interpersonal trust in the success of IMF program engagement. Analogously, it provides some indications about how distrust can contribute to program failure. On the one hand, trusting relationships between IMF staff and program country authorities are shown to eventually contribute to improved program design, smoother negotiation process, and better track record of program implementation. On the other hand, several risks to successful program design, negotiation, and implementation associated with a low level of trust are identified, including personality clashes, high expected or actual costs of negotiation, provision of IMF Board-unendorsed staff's advice, and linguistic barriers.

After describing what this paper aims to do, it is useful to indicate what the paper does not attempt to do. This work does not pretend to set forth an encompassing methodology for measuring the level of trust in the context of all working relationships between staff and member country authorities. Given the multifaceted aspects and various characteristics of trust, the measurement of trust may depend on country specific circumstances and the type of IMF activities that staff undertakes. Certainly, trust-related issues emerge prevalently in the context 
of surveillance and technical assistance, with far-reaching implications for the effectiveness of these activities. Also, effective surveillance and technical assistance may probably require a different level and importance of trust between IMF staff and country authorities than is needed in a program context.

Furthermore, this paper does not address all forms of trusting relationships between all actors involved in the design, negotiation, and implementation of an IMF-supported program. A high level of trust between country authorities and IMF staff is a necessary but insufficient condition for ensuring program success. Indeed, it needs to be complemented by trusting relationships between all categories of IMF personnel, including the Executive Board, Management, and staff on the one hand, and between IMF personnel and country authorities on the other. In particular, trusting relationships between the Executive Board, Management, and staff are clearly critical not only for program-related work but also for the effectiveness of all other IMF's activities. Thus, further investigation of intra-organizational trust issues can help better elucidate how such relationships can be nurtured and strengthened. However, this notion of trust is beyond the scope of this paper and is not explored below.

The remainder of the paper is structured as follows. Section II provides a brief and selective survey of the literature on trust. Section III addresses specifically trust-related issues emerging in the context of an IMF-supported program. Section IV proposes an outcomes-based modeling framework that attempts to capture some of these issues. Section V derives key policy implications for program success and trust building.

\section{SELECTIVE REVIEW OF THE LITERATURE ON TRUST}

\section{Definitions of trust}

In spite of the abundant literature on trust issues, the numerous authors involved still struggle to find common grounds when it comes to defining trust. Among the causes of this imbroglio is the fact that trust is a multifaceted notion with direct relevance to multiple disciplines, including psychology, sociology, philosophy, economics, law, political science, history, health care, anthropology, and computer science. Various dictionaries provide a range of definitions that typically characterize trust as a firm reliance on the integrity or the ability of a person or a thing; a certainty in another party's trustworthiness; confident expectations of something; and a condition in which one is free from doubt. All in all, trust is deemed to involve a great deal of belief about the honesty and the reliability of others or, in other words, the expectancy that others are honest and reliable.

Among the numerous definitions of trust that are used in the literature, some have been recurrent. First, trust has been characterized as a confidence or predictability in one's expectations (Luhmann, 1979, Zucker, 1986). The concept of trust as predictability is meant to refer to the probability with which a party estimates that another party will act in a certain way. Under this definition, an actor is trusted by another one if the latter is confident that one's predictions about the behavior of the former will come true. This concept of trust is deemed to promote cooperation by coordinating social interaction (Gambetta, 2000). However, the notion of trust as predictability has been extensively criticized. Bhattacharya et al. (1998) find little 
interest in the predictability aspect of trust which they define as an evaluation of the uncertainty characterizing the relationship between the actions taken by the parties and their subsequent outcomes. These authors insist that trust is not an expectation even though it can embody it. Other authors have also stressed the importance of making a distinction between trust-based interactions and power-based interactions which produce different forms of cooperation.

Second, trust has been also defined as confidence in the other's goodwill, with cooperation being given precedence over confrontation or opportunistic behavior (Ring and van de Ven, 1992). This notion of trust relies on the existence of common values that can generate convergent goals or a sense of community. Hardy, Phillips, and Lawrence (1998) question the validity of such an assumption, especially in the context of relations between organizations which may have different values and goals and be subject to pressures from different constituencies. In addition, they stress that the idea of goodwill-based trust generates a set of questions on the origin, foundation, and signaling of goodwill that give rise to different answers.

Besides predictability and goodwill, however, some definitions of trust have attempted to capture other aspects of trust. For instance, Hardy, Phillips, and Lawrence (1998) include in the definition of trust the idea that there is high expectation from each party that others will not engage in opportunistic behavior. For Bhattacharya et al. (1998), trust is an expectancy of favorable outcomes that one can receive based on the expected action of another party and, as such, it may not need to emerge in an interaction characterized by certainty only. Chami and Fullenkamp (2002) consider trust as a high level of mutual altruism.

\section{Characteristics of trust}

Despite the numerous and heterogeneous definitions of trust, most authors seem to agree on various characteristics of trust. First, there is a consensus that trust is a desirable property of the relationships between individuals, organizations, and institutions. The importance of trust is reinforced by the fact that trust is a concept that can facilitate the occurrence of positive outcomes. The desirable features of trust include its ability to promote cooperation, which may be preferable to competition under certain circumstances (La Porta, Lopez-de-Silanes, Shleifer, and Vishny 1997, Gambetta, 2000).

The second and third characteristics of trust emphasized by some authors including Bhattacharya et al., (1998) relate to the situation- and person-specific nature of trust and its relationship with vulnerability. Because trust is situation- and party-specific, a party's trust level can evolve depending on the actions taken by other parties as well as the expected outcomes and consequences of these actions. Vulnerability is considered as a key facet of trust. Trust implies an implicit acceptance of being vulnerable to the actions of the trusted party coupled with an expectancy that the latter will act favorably to one's interests.

Fourth, trust involves a great deal of uncertainty and risk, which must not be confused with vulnerability. The existing literature conceptualizes trust only against the background of uncertainty and finds an inherent relation between risk and trust. However, the nature of the relation between trust and risk remains subject to controversy. On the one hand, some consider trust as a way to reduce risks associated with economic transactions. Ring and Van de Ven 
(1992) argue that, all else being equal, the greater the ability to rely on trust, the less the risk inherent in a transaction. On the other hand, there are proponents of the view that trust constitutes a risk to effective transactions between partners. For instance, it is often argued that the less an agreement depends on trust, the more likely it is to be implemented (Fisher, 1991).

Fifth, trust can be a functional equivalent of power since the latter can also ensure predictability in coordination (Hardy, Phillips, and Power, 1998). Trust and power can exert similar effects on a party's decision to act in an expected way. An actor can indeed act as expected by someone, not on the basis of trusting relationship, but out of fear of the power of the expectant or possibly another actor. However, as noted by Hardy, Phillips, and Lawrence (1998), the use of power reduces synergy even though it may increase predictability and serve the purposes of the dominant partner.

Finally, trust is not trustworthiness. As suggested by Chami and Fullenkamp (2002), a model of trustworthy behavior is an incomplete model of trust. Different parties that do not trust each other can be provided with incentives to act in a trustworthy way. Unlike trust, trustworthiness does not necessarily include cooperation-promoting incentives.

\section{Sources of trust}

Although some authors argue that trust emerges spontaneously (see for instance Sabel, 1993), many studies undertaken across the literature provide various explanations about the sources of trust. Trust is deemed to originate, among others, from the institution of relevant procedures (Zucker, 1986); norms of equity which define the degree to which one party judges that another will fulfill its commitments and that the relationship is equitable (Van de Ven and Walker, 1984); the exhibit of appropriate symbols (Lewis and Weigert, 1985); successful and repeated transactions between parties observing the norms of equity (Dasgupta, 1988; Ring and Van De Ven, 1992); and a communication process in which shared meanings develop to support nonopportunistic behavior (Hardy, Phillips, and Lawrence, 1998).

\section{Trust In THE CONTEXT OF AN IMF-SuPPORTED Program}

As previously noted, trust in the context of an IMF-supported program is defined in this paper as an expectancy of positive or nonnegative outcomes from which IMF staff and a member country's authorities can benefit based on each other's expected action. In many ways, this definition, in line with Bhattacharya et al. (1998) who conceptualize trust in an environment characterized by uncertainty, is relevant to working relationships between program country authorities and IMF staff. First, a program relationship is expected by both parties to produce positive outcomes which can be assimilated to program objectives. Second, the definition confines the study of trust in the context of a program relationship which is, a priori, marked by uncertainty with regard to the quality of the IMF staff's advice, the outcome of its implementation, and the type of actions to be subsequently taken by country authorities. Indeed, staff's expectations of the actions taken by the authorities are not always met in a program context. Likewise, the authorities may have beforehand presumptions about staff's advice that depart from their final appreciation of it. 
IMF engagement in a program country can be deemed successful if it effectively helps reach the objectives of the country's IMF-supported program. These objectives which are common to the IMF and the program country typically include the restoration of external viability and macroeconomic stability, the promotion of growth, and the reduction of poverty. However, the IMF's task of assisting the country in achieving these objectives is not always straightforward. On the one hand, this task is often made difficult by the lack of a deterministic relationship between IMF staff's advice and the actual outcomes of program implementation. On the other hand, the extent to which staff's advice is implemented can play an important but not necessarily exclusive role in program success or failure. Although strong implementation of IMF staff's advice is likely to help achieve program objectives, it can nonetheless coincide with total program failure in the sense of unmet objectives. Conversely, program objectives may be reached in spite of weak implementation of staff's advice. This implies that an IMF-supported program can be successful in the above sense of the word even though the program country has a poor track record of implementation of staff's advice.

Trust issues can emerge in various stages of IMF program involvement. Figure 1 below provides an illustration of the set of dependencies between the concept of trust and various stages of a program relationship. It shows that an efficient process of negotiation, design, implementation, and monitoring of an IMF-supported program builds upon trust between IMF staff and country authorities.

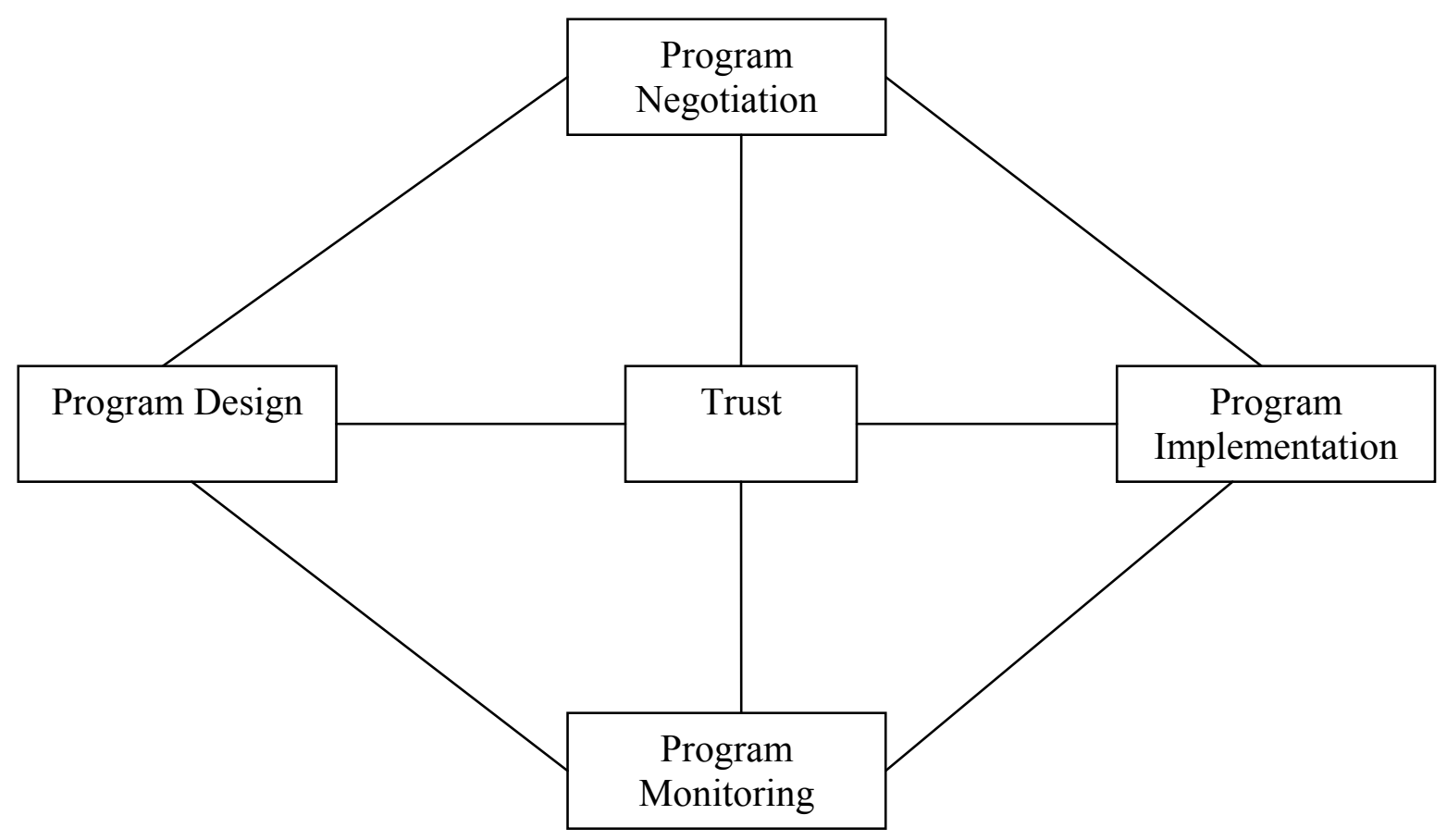

Figure 1. Dependency Map

Clearly, the chart does not necessarily capture all dependencies between the design, negotiation, implementation, and monitoring of an IMF-supported program. It captures, however, the idea that the level of trust or distrust prevailing between IMF staff and the authorities is affected by past IMF involvement in the program country. As Ring and van de Ven (1992) point out, the 
more frequently the parties have successfully transacted, the more likely they will bring higher levels of trust to subsequent transactions. By analogy, a high proportion of successful past IMFsupported programs can help strengthen trust between IMF staff and country authorities. In contrast, repeated past program failures can lead to a higher level of distrust between the two parties in subsequent program relationships, with potentially adverse implications for the quality of the dialogue between the IMF and the program country. This is a reflection that reputation plays an important role in program success. ${ }^{6}$ IMF's reputation in a program country-and even in others-matters in that it can influence heavily the country's decision as to whether or not to implement IMF's advice. Likewise, the reputation of the program country which can be for instance its implementation track record in a program context is a key determinant of the likelihood of program success.

When facing balance of payments difficulties or aiming to prevent crises, a member country can request an arrangement with the IMF. In order to make such a request, it sends a letter of intent (LOI) to the IMF in which it presents the economic program for the implementation of which IMF assistance is sought. ${ }^{7}$ After the country has expressed its interest in an IMF arrangement, the process of negotiating and designing a program that can be supported by IMF resources is launched. Such a program is assigned a number of economic objectives linked to a set of macroeconomic and structural policies specified through the use of IMF analytical tools and economic judgment. Through an internal review process, a brief is prepared for the IMF negotiating mission, summarizing proposed staff reaction to the authorities' program and assessments of potential implementation obstacles. Upon the completion of the process of program design and negotiation, the proposed IMF-supported program is submitted for consideration to the IMF Executive Board. As such, the process of designing and negotiating an IMF-supported program involves various stages. At each stage, a number of trust-impacting issues are likely to emerge in various ways.

This section explores a variety of factors that can affect trust during the process of program design, negotiation, and implementation. Although the design and negotiation of a program can be two concurrent stages in practice, they are considered separately for tractability purposes.

\section{A. Trust and Program Design}

In the context of program design, various issues can come up and likely affect the level of trust between the authorities and IMF staff. Such issues tend to have an impact on trust in that they emerge in situations where a party's expected actions are likely to produce outcomes that are favorable or unfavorable to the other party.

\footnotetext{
${ }^{6}$ Carter and Ghorbani (2002) argue that an agent with an excellent reputation is guaranteed to be trusted by everyone.

${ }^{7}$ A memorandum of economic and financial policies may or may not be attached to the LOI. In cases where some confidential information needs to be preserved, a "side letter" may also be sent by the authorities to IMF Management or staff.
} 


\section{Trust in IMF staff}

From the authorities' perspective, issues with a potential impact on their level of trust in the staff can emerge in many ways in the context of program design, depending, in particular, on how sound and timely staff's advice is perceived to be, where it is believed to originate from, and how IMF personnel handles potentially sensitive information provided by the authorities.

\section{Origin and timing of staff's advice}

The alleged origin of staff's advice from the authorities' perspective may be a key determinant of the level of trust that staff enjoys. It is likely to be a key source of distrust in the staff if there is a suspicion from the authorities that the provision of a specific staff's advice stems from pressures by other domestic and external stakeholders. Such distrust can be exacerbated by perceptions that the latter are believed to benefit primarily from the implementation of that specific advice.

Irrespective of the quality of staff's advice, the authorities are likely to question the adequacy of its timing if they suspect its implementation to generate outcomes that are potentially unfavorable to the program country or themselves. This is often the case in situations where a specific staff"s advice is provided during a period deemed "sensitive" and its implementation not suitable from the authorities' standpoint. And because of the authorities' expectation that the implementation of staff's advice will generate negative outcomes for the program country or themselves, trust in staff is likely to be adversely affected. For instance, in the run-up to elections, staff's advice is most likely to backfire on the level of trust in staff if it is expected by the authorities to be associated with negative outcomes. However, it is noteworthy that the timing of a specific staff's advice may not have a significant impact on the level of trust in cases where this advice has continuously been provided before the "sensitive" period, but not followed up with by the authorities.

\section{Expected quality of staff's advice}

During the policy formulation process undertaken in the context of program design, country authorities have conjectures or beliefs about the quality of IMF advice that affect their level of trust in the IMF. Through the authorities' conjectures, trust in IMF staff is likely to be influenced by the extent to which staff's advice is believed to generate favorable outcomes for the aspiring or active program country. These conjectures may be derived from past interactions with staff as well as a comparative analysis of previous staff's advice, within and outside a program context. Hence, the expected quality of staff's advice is, from the authorities' perspective, a key determinant of their level of trust in staff in subsequent program relationships. However, there may be a two-way relationship between trust and the expected quality of staff's advice since the level of trust in staff can also be among the key arguments that enter in the formation of the authorities' expectations about the quality of staff's advice. 


\section{Handling of sensitive information}

The extent to which the authorities believe that sensitive information provided to the IMF may somehow leak as a result of mishandling by IMF personnel is likely to affect their level of trust in the staff. Country authorities expect the IMF, as their trusted and confidential advisor, to safeguard the confidentiality of information that they provide to the institution and they deem not suitable for public access. Under these circumstances, the authorities' trust in IMF staff is clearly at jeopardy in the event of a leak supposedly due to mishandling of this information by IMF personnel. In such a case, the program at stake may, if successfully designed and concluded, face a lower likelihood of success as a result of both the disclosure of the sensitive information and its trust-reducing effect.

\section{Trust in country authorities}

In the context of program design, staff's trust in the authorities can be influenced by the perceived commitment of the latter to sound program design. Indeed, because of its direct link to IMF staff's conjectures, the perception of the credibility and strength of this commitment likely affects the level of trust that the authorities can enjoy from staff. The credibility and strength of commitment by the authorities to sound program design can be perceptible through their response to staff's proposed policy measures, their actual contribution during the process of program design, and their treatment of staff's advice in the context of other IMF activities.

\section{Response to proposed policy measures}

As previously suggested, staff's advice during the process of program design includes a package of macroeconomic and structural policies. It summarizes the set of policies that staff deems appropriate for an IMF-supported program given the country's specific circumstances. Naturally, staff's advice is not necessarily always in line with the authorities' homegrown policies. IMF staff and the authorities can have different viewpoints on the type of policy actions that are deemed appropriate under certain circumstances. Such differences of views are most likely to surface in situations where proposed policy actions and program objectives are not explicitly linked by a deterministic relationship. In these situations, the level of trust that staff has in the authorities can be affected by its perception of the cause of the authorities' resistance to its proposals. For instance, staff's level of trust can be reduced if the authorities' resistance to key structural conditions that staff deems critical for program success is believed to be motivated by unfounded arguments.

\section{Contribution to program design}

If interactions between the authorities and IMF staff are neither power-based nor capacityconstrained, the extent to which country authorities effectively contribute to the process of policy formulation can signal the credibility and strength of their commitment to sound program design. In this context, the authorities can be expected, if strongly committed, to be actively involved in this process and to have a high propensity to provide staff with complete and accurate information in a timely manner. Clearly, staff's assessment of the degree of this involvement and this propensity is a key determinant of the level of trust in the authorities. At 
the same time, this assessment can also be influenced by the level of trust that staff has in the authorities. For instance, a low level of trust in the authorities will lead staff to expect from them a low propensity to provide full information.

\section{Treatment of staff's advice in the context of other IMF activities}

The expected treatment by the authorities of staff's proposed policy measures can also signal the authorities' commitment to sound program design. The actual treatment of previous staff's advice in the context of other IMF activities such as surveillance and technical assistance appears to be a good - albeit imprecise - indicator of the possible handling of such advice in a program context. In the conduct of these activities, staff develops its perception of the credibility of the authorities' commitment to both the design of a sound IMF-supported program and the implementation of IMF's advice. As the member country requests an IMF arrangement, this perception may influence the level of trust that the authorities can enjoy from the IMF.

\section{Importance of trust for sound program design}

Trusting relationships between IMF staff and program country authorities provide a favorable context for sounder program design. In part, this stems from the ability of trust to promote cooperation, which, coupled with other characteristics of trust, explains the positive impact of trust on the quality of program design. There are a number of channels through which trust can impact on program design. First, it follows from the above exposé that trusting relationships are likely to be associated with lower informational costs to program design than those that are held in a distrusted environment. In this context, trust can contribute to enhancing program design by reducing potential information asymmetries between the IMF and the program country. This is likely to result from the stronger propensity of the authorities to provide accurate and complete information when feeling a high level of trust in the IMF. ${ }^{8}$

Second, the potential of trust to contribute to sounder program design can also relate to the twoway causality between trust and country ownership of the IMF-supported program. Country ownership may enhance trust by reducing the accountability of the IMF for unfavorable outcomes of program engagement. Conversely, the higher the level of trust is, the more likely it is for the country to be in the driver's seat during the process of designing the program and ensuring its timely implementation. Thus, trust may contribute to strengthening program ownership by increasing the prospects for the country to play the primary role in program design and the conduct of program implementation. ${ }^{9}$

\footnotetext{
${ }^{8}$ It is however noteworthy that there may be some instances where inaccurate information is unintentionally provided to the IMF, and thus irrespective of the level of trust in the institution.

${ }^{9}$ Lack of ownership is seen as a frequent reason for implementation problems. See, for instance, IMF (2006).
} 
Third, trust can affect program design through its positive impact on performance. ${ }^{10}$ The more trusted a party feels it is, the more likely it behaves so as to deserve this trust. In a program context, interpersonal trust between IMF staff and country authorities can lead either party to make additional efforts in order to meet the other party's expectations.

\section{B. Trust and Program Negotiation}

This section outlines a number of trust-impacting risks to smooth negotiation of an IMFsupported program. Afterwards, it stresses the importance of trust for a successful program negotiation.

\section{Trust-impacting risks to successful program negotiation}

There are indications that the success of program negotiation is faced with several trustimpacting risks. This section raises only those risks that can potentially affect trust between the authorities and staff. It does not address other issues that are beyond the scope of this paper and which involve trust between country authorities and other categories of IMF personnel, including the nature of trusting relationships between the authorities and IMF Management and the level of intra-organizational trust at the IMF - particularly between IMF Management and staff. For instance, during the IMF review process preceding program negotiation, potential gaps that surface between Management and the staff team can constitute serious risks to the authorities' trust in staff. In case Management's position is deemed more favorable to the program country, awareness of those gaps by the authorities may undermine their trust in staff and tempt them to short circuit the negotiation process and negotiate directly with IMF Management.

Potential risks to trust between the authorities and staff include personality clashes, high costs of program negotiation, linguistic barriers, and the provision of Board-unendorsed staff's advice.

\section{Personality clashes and demographic characteristics}

One of the key risks to the success of program negotiation relates to the possibility of personality clashes. Typically, negotiation of an IMF-supported program entails interactions between the IMF mission team and country authorities both in the field and remotely. Under these circumstances, trust issues tend to be more of interpersonal rather than interorganizational order, whereby trust or distrust are likely to involve primarily the mission team members and their country counterparts. In this context, conflictual interactions between the two parties are likely to beget interpersonal distrust.

\footnotetext{
${ }^{10}$ See, for example, McEvily et al. (1998) and Chami and Fullenkamp (2002) on the effects of trust on individual performance. A segment of the literature also finds robust evidence of the impact of trust on economic performance. Mirakhor (2005) presents an interesting survey of this literature.
} 
Moreover, as shown by many studies, interpersonal trust can possibly be influenced by demographic characteristics. ${ }^{11}$ During the process of program negotiation, such characteristics may impact on the level of trust through the conjecture of each party about the actions and motivations of the other party. Hence, negotiation of an IMF-supported program is not immune to the risks of personality clashes, along with potential implications on the ultimate IMF's response to the authorities' request for an arrangement.

\section{Costs of program negotiation}

Another trust-impacting risk that may arise in the course of program negotiation stems from the estimated negotiation costs. It is often argued that trust reduces the costs of negotiation which include the time and efforts spent to reach an agreement. ${ }^{12}$ In this sense, it would seem that the lower the level of trust between staff and the authorities, the more difficult and costly it is to reach understandings on the details of an IMF arrangement. In turn, the expected negotiation costs of an IMF-supported program can influence the level of trust that both parties have in one another. In theory, the level of such costs can reveal, from the authorities' perspective, the strength of the IMF's commitment to program engagement. At the same time, it may well be viewed by IMF staff as signaling the extent to which the authorities are effectively committed to the program being negotiated.

\section{Linguistic Barriers}

Given that English is the IMF's working language, a lack of fluency in it by country authorities can undermine the quality of their policy dialogue with IMF staff, thereby constituting a key impediment to an efficient program negotiation. In such situations which typically arise in cases where IMF staff's fluency in the authorities' language is also limited, it can be difficult for either party to take fully advantage of its personal negotiation skills when communicating with the other party. This inability of IMF staff and the authorities to add a personal touch to the negotiation process may constrain their efforts to build mutual trust. The recourse to language interpretation services does not necessarily eliminate this problem, although it helps reduce its scope. In fact, in some instances, trust building can be adversely affected by the provision of interpreters. Indeed, this assertion is obviously relevant when the service provided by the latter is not of good quality. But it is also relevant even in the presence of highly skilled interpreters because, as a third party involved in the negotiation process, they reduce inevitably the scope for negotiators to build interpersonal trust through direct interactions.

\footnotetext{
${ }^{11}$ See for instance Bohnet and Hong (2004). These authors examine how demographic characteristics such as culture, gender, age, and ethnic background impact on people's willingness to accept trust-related risks such as the risk of being worse off than if they had never trusted, the risk of being worse off than the trusted party, and the risk of being betrayed by the trusted party. See also the empirical study conducted by Alesina and La Ferrara (2000) about the influence of individual and community characteristics on trust.

${ }^{12}$ Zaheer, McEvily, and Perrone (1998) support this argument. They define negotiating costs as those involved in reaching mutually acceptable agreements. Specifically, these costs are deemed to be an increasing function of the level of uncertainty, information asymmetries, and bounded rationality related to the imperfect communication and observation and verification problems.
} 


\section{Provision of Board-unendorsed staff's advice}

It is noteworthy that staff's advice becomes effectively IMF's advice only after it is endorsed by the IMF's Executive Board. Staff's advice provided during program negotiation may run the risk of altering the authorities' trust if it is not endorsed by the Executive Board. It is clear that, during the process of program design and negotiation, staff's advice and actions are generally consistent with existing operational guidelines based on Board-approved procedures. However, in the course of program negotiation - particularly those conducted in the field - unexpected country-specific issues may arise for which proper Board guidance is lacking or unclear. Under these circumstances, trusting relationships between staff and the authorities are at risk of being severely damaged in the case of a provision of staff's advice that proves to be inconsistent with Board-approved policies. However, it is worth noting that the risk of provision of Boardunendorsed staff's advice is usually quite low. The ad referendum nature of negotiation of an IMF-supported program gives little incentive for IMF Management and, ultimately, the Board to overrule staff, given the adverse impact of such a decision on the authorities' trust in staff. In addition, staff can always contact IMF headquarters by rapid means of communication to get a clearer sense of existing procedures or the best approach to be adopted.

\section{Importance of trust for successful program negotiation}

Trust plays a key role in determining the outcome of the negotiation process. By minimizing the abovementioned costs and risks to program negotiation, trust can increase significantly the probability of successful completion of this process. Like in the context of program design, some characteristics of trust, such as its ability to promote cooperation and boost performance, may also have positive implications for the outcomes and timeliness of the negotiation process.

In addition, a number of factors may help engender trust during program negotiation and enable it to fulfill its potential role. On the one hand, these factors include staff's familiarity with IMF procedures and analytical tools, mastery of macroeconomic analysis, and good knowledge specific circumstances of the program country, which can help staff provide the authorities with good customized advice consistent with IMF Board-endorsed policies. On the other hand, strong individual and interpersonal skills of both staff and country authorities are trust-inducing factors that generally contribute to successful program negotiation. In particular, if at least chief negotiators of both parties have strong communication and negotiation skills, chances for a successful completion of the negotiation process are then higher.

\section{Trust And Program Implementation}

At the stage of program implementation, issues with a potential impact on the level of trust between the authorities and the staff can also emerge. Such issues are likely to affect trust by influencing each party's expectancy of favorable or unfavorable outcomes. This section addresses these issues and, then, stresses the importance of trust for effective program implementation. 


\section{Trust-impacting factors during program implementation}

The level of trust between staff and the authorities may be relatively easier to determine if the aspiring program country has had previous relationships with IMF staff within — and to some extent outside - a program context. In such situations, IMF staff already avails itself of more or less precise conjectures about the credibility of the authorities' commitment to implement its policy advice. In this context, the authorities in countries with an excellent track record of implementation of IMF's advice would probably be assumed to be trustworthy and trusted to engage in effective and timely program implementation. Similarly, through their firmer conjectures about staff's advice, country authorities can develop more informed views on the trustworthiness of staff.

Nevertheless, whether or not IMF staff and the authorities have had previous relationships, trusting relationships between the two parties can be influenced by several factors in the program implementation phase. Among others, such factors include the motivation of the request for, and form of IMF arrangement, the perceived quality of staff's advice, the outcomes and consequences of program implementation, the relationship between the actions and outcomes, the expected consequences of outcomes, and the estimated costs of program implementation.

\section{Motivation of the request for, and form of, an IMF arrangement}

The motivation of the request for an IMF arrangement and the form of the requested arrangement can oftentimes signal the extent to which the authorities can be trusted to be motivated by a real desire to fully implement the requested arrangement in a timely manner. Under certain circumstances, a country's authorities can be expected to be relatively more committed to implementing staff's advice in the context of an IMF-supported program that is designed for crisis resolution purposes than it would be in the case of program aiming at preventing a crisis. Indeed, the occurrence of a crisis induces some sense of urgency which, combined with the obligation of immediate positive results on the part of the authorities, contributes to increasing the expected relative benefits of a successful program implementation. Moreover, precautionary arrangements that are not solely intended to play a catalytic role are likely to signal a readiness to implement IMF's advice, given that such arrangements are typically made in the absence of immediate balance of payments need. In contrast, a country with an immediate need for IMF resources or signaling may have fewer incentives to implement staff's advice once its financing and signaling needs are addressed.

\section{Perceived quality of staff's advice}

Clearly, the quality of staff's advice, as perceived by the authorities of the program country, exerts inevitably an impact on their trust in the staff and their eagerness to implement the advice. Assuredly, in cases where staff's advice is deemed to be sound, the authorities' trust in the staff is likely to be strengthened, increasing the prospects for effective program implementation. In contrast, trust in staff tends to be damaged if its advice is viewed by the authorities as flawed. However, there is no reason to suppose that the impact of the quality of staff's advice on the authorities' trust is necessarily symmetrical. Indeed, the provision of a 
staff's advice deemed good by the authorities does not necessarily strengthen the latter's trust in staff in the same way as the provision of a staff's advice perceived as flawed may weaken it.

\section{Outcomes and consequences of the implementation of staff's advice}

The actual and expected outcomes of the implementation of staff's advice in a program context can have major implications on the level of trust between staff and the authorities. From the authorities' perspective, the level of trust in the IMF and its staff is an increasing function of the probability of outcomes deemed favorable to the program country and its authorities. The higher this probability is, the higher the level of the authorities' trust in the IMF is. Alternatively, their level of trust is low when the likelihood of IMF's advice to generate unfavorable outcomes is small. From the perspective of IMF staff, trust in country authorities may also depend on how favorable the actual or expected outcomes of the implementation of staff's advice are to the IMF and itself. Since the consequences of this implementation are determined by these outcomes, stronger trusting relationships are likely to be induced by the prospects of positive consequences for both parties. Analogously, such relationships are likely to deteriorate if the implementation of staff's advice leads or is expected to lead to negative consequences.

\section{Relationship between the quality of staff's advice and the outcome of its implementation}

From the authorities' standpoint, trust in IMF staff is influenced by the relationship between the perceived quality of the latter's advice and the actual and expected outcome of the implementation of this advice. Clearly, if the relationship is deterministic, this reduces to the predictability aspect of trust, with the perceived quality of staff's advice being a key element. But, if it is characterized by uncertainty, as is often the case in a program context, then issues of trust and distrust in the IMF are prevalent. In this case, the level of the authorities' trust in IMF staff is indeed likely to increase if the actual or expected outcomes of the implementation of staff's advice are considered by the authorities as favorable to their country and themselves. This is a direct implication of the notion of trust defined as an expectancy of positive outcomes from which the program country and its authorities can benefit from based on staff's expected advice. In contrast, the level of trust enjoyed by staff may decrease if the actual or expected outcomes of the implementation are deemed to be unfavorable from the perspective of country authorities.

\section{Costs of program implementation}

The estimated and actual costs of the implementation of staff's advice may be among the key determinants of the level and strength of trust that IMF staff and a program country's authorities have in each other. Indeed, the magnitude of such costs which may be of economic, political or social order can be expected to be positively correlated with the probability of obtaining favorable outcomes in relation to the implementation of staff's advice. The acceptance of significant implementation costs by country authorities tends to signal their expectancy of, and commitment to achieve, positive outcomes. At the same time, higher implementation costs contribute to increasing the potential reputational damage to the IMF and its staff in case of program failure, which intensifies the latter's hunger for program success. This reinforces the incentives for both parties to make the efforts needed to ensure program success. 


\section{Importance of trust for effective program implementation}

In light of the above, the importance of trust for program implementation cannot be stressed with enough emphasis. A key question for the authorities is whether staff can be trusted enough for the implementation of its advice to be warranted. A case for the implementation of staff's advice requires that it be expected to generate positive outcomes for the program country and its authorities, which tends to necessitate a high level of trust in staff. In turn, the authorities' trust in staff builds upon a number of factors, including the quality of staff's advice; the outcomes, consequences, and costs of its implementation; and the relationship between the quality and implementation outcome of staff's advice. The more staff's advice is deemed by the authorities to be associated with favorable outcomes and desirable consequences for the program country, the more likely it is to be trusted and implemented. In contrast, it is likely that a country with a high level of distrust in the IMF might subsequently register a poor record of implementation of IMF policy advice in the program context. Still, program implementation may indeed proceed in a distrusted environment, but it is most likely that this would come at the expense of its timeliness.

Thus, given that trust is not the unique determinant of program implementation, the answer to the authorities' question needs to be supplemented by other country-specific considerations, including the expected benefits and costs of implementation, and the need for IMF resources or catalytic role. Furthermore, the implementation of a specific staff's advice can be, in some instances, the outcome of trust-unrelated interactions between the country's authorities on the one hand and the IMF or other stakeholders on the other.

Like in the context of program design and negotiation, the positive impact of trust on program implementation can also channel through performance. From the perspective of the authorities, satisfactory performance under an IMF-supported program is often motivated by a specific need for establishing a track record of implementation of IMF's policy advice. At the interpersonal level, higher performance by staff or the authorities can be driven by the feeling of being trusted.

\section{AN OUTCOMEs-BASEd MOdel OF TRUST}

In light of the analysis made in previous sections, a game-theoretic, outcomes-based model is developed in this section in an attempt to capture some of the trust related issues emerging in the context of an IMF-supported program.

Suppose a sequential-action case where, in the stage of program design and negotiation, IMF staff moves first to provide either a preferred or an unpreferred advice from the perspective of the program country authorities. It is natural to suppose that the authorities have their own perceptions or beliefs about staff's advice that are based, for instance, on previous interactions with staff, the outcomes of the implementation of previous staff's recommendations, and the comparison of staff's advice with homegrown policies as well as those implemented, supposedly under IMF's influence, in other countries with similar circumstances. These factors influence, in particular, the authorities' perception of the quality of staff's advice. Given their 
beliefs about staff's advice, it is assumed that the authorities can clearly differentiate between the preferred and the unpreferred staff's advice. A less trivial but sensible assumption which is also made is that IMF staff is aware of the authorities' appreciation of its advice. This awareness can be developed, for instance, during the process of program design and negotiation, when interactions with the authorities allow staff to observe their initial reaction to its advice.

In the subsequent stage of program implementation, the program country's authorities can choose between implementing and not implementing the IMF staff's advice. The authorities' choice of the course of action may depend on a number of factors, including their perception about the quality of such advice, the outcomes of its implementation, and the expected benefits and costs of action versus inaction. This presumes that, in some instances, staff's advice can be preferred by the authorities but remains not implemented because of its expected high costs - of social or political order for instance. Conversely, an unpreferred staff's advice can be implemented if, for example, the benefits of having an active IMF-supported program largely exceed the costs associated with the implementation of this specific advice.

Let the action profile $\left(a_{S}, a_{C}\right)$ denote a combination of actions that IMF staff and the program country's authorities - indexed respectively by $S$ and $C$ - can take and $A_{S}$ and $A_{C}$ are their respective action space. Mathematically $a_{S} \in A_{S}$ and $a_{C} \in A_{C}$, where $A_{S}=\{$ preferred; unpreferred $\}$ and $A_{C}=\{$ implement; not implement $\}$.

The actions taken by staff and the authorities are assumed to jointly but randomly determine the actual outcomes of IMF program engagement denoted $x$. IMF staff and country authorities have the same outcome space, $X$, which can include, for instance, the impact of the actions taken by the IMF staff and the authorities on growth, inflation, fiscal balance, and the current account. Thus, actions are translated into outcomes through a random function $\theta$. This implies that the causal relationship between actions and outcomes is not always known with certainty and the function $\theta$ randomly takes values in $X$ the finite set of all possible outcomes for the IMF and the program country. In other words, a given action profile $\left(a_{S} ; a_{C}\right)$ can generate different outcomes if taken repeatedly. For instance, the objectives of a multi-year IMF-supported program can be met in one year but unmet in another even though the country's authorities have consistently implemented what they sense as preferred staff's advice.

Therefore, if IMF staff and country authorities take actions $a_{S}$ and $a_{C}$, respectively, the probability of a specific outcome $x$ is

$$
\operatorname{Pr}\left(\theta=x \mid a_{S}, a_{C}\right)=F\left(x ; a_{S}, a_{C}\right) .
$$

As such, the model applies to any program relationship between a member country and the IMF regardless of how knowledgeable IMF staff is of the actual outcomes of program implementation. However, allowing for the possibility that information might be imperfect is important since both parties may have sometimes different perceptions about such outcomes or at least one party may have an inaccurate appreciation of actual outcomes. Such situations can arise for instance as a result of measurement problems or misreporting by the authorities. 
Suppose $x+\varepsilon_{i}$ denotes the outcomes of IMF program engagement as perceived by party $i$ which is either IMF staff or country authorities.

Whether or not the IMF-supported program is implemented, there are outcomes that will have positive or negative consequences on the level of satisfaction or dissatisfaction of the IMF and that of the program country. For instance, continued program engagement stemming from successful program implementation allows the institution to enjoy, through the continuation of its lending activities, the satisfaction generated by the fulfillment of one of the key aspects of its mandate. With prolonged use of its resources, the IMF can also expect additional income arising from interest payments made by the program country in relation with the existing IMF arrangement. Alternatively, a program that goes off-track entails an expected income loss for the IMF. In addition, the IMF can bear reputational costs if program implementation is presumed to have generated negative outcomes. From the perspective of the program country, the implementation or lack of implementation of an IMF-supported program are associated with outcomes that have potentially major implications on the soundness of economic and social indicators such as employment levels, poverty rates, external viability ratios, and the likelihood of occurrence or resolution of a crisis.

Let $U_{S}$ and $U_{C}$ denote the consequences of the outcomes for the IMF and the program country respectively. Naturally, staff and the authorities aim at securing positive consequences for the IMF and the program country respectively. For simplicity, suppose the functions $U_{S}\left(x+\varepsilon_{S}\right)$ and $\left(U_{C} x+\varepsilon_{C}\right)$ are normalized so that they take positive (negative) values for perceived outcomes $x+\varepsilon_{S}$ and $x+\varepsilon_{C}$ favorable (unfavorable) for the IMF and the program country. For instance, an unfavorable outcome to both parties may consist in, say, a negative impact of the lack of implementation of a specific staff's advice on growth, inflation or the fiscal stance. Conversely, a favorable outcome may relate to the positive implications of staff's advice for the program country's economic situation. ${ }^{13}$ Therefore, the set of all perceived outcomes that are favorable to party $i, \Omega_{i}$, can be written as follows

$$
\left\{\quad: \quad \Omega_{i}=x+\varepsilon_{i} \in X \quad U_{i}\left(x+\varepsilon_{i}\right)>0\right\} \cdot(2)
$$

If IMF staff and the authorities take actions $a_{F}$ and $a_{C}$, then the probability of obtaining an outcome favorable to party $i$ is the sum of the probabilities of obtaining each specific outcome over the set of all outcomes favorable to this party, that is $\operatorname{Pr}\left(U_{i}>0 \mid a_{i}, a_{j}\right)$. Conversely, the probability of obtaining an outcome unfavorable to party $i$ is given by $\operatorname{Pr}\left(U_{i}<0 \mid a_{i}, a_{j}\right)$. This probability gives also an indication of the vulnerability of each party to the action taken by the other one.

\footnotetext{
${ }^{13}$ The possibility that a specific outcome is perceived as favorable to one party but not to the other cannot be ruled out. In particular, this situation may occur as a result of potential differences in the ways the two parties perceive outcomes and interpret the relationships between these outcomes and their respective actions.
} 
Each party has beliefs about the actions of the other party, which are called a priori conjectures. IMF staff can expect that the authorities will take an action over another, given the country's track record of program implementation, specific country circumstances, and the credibility of the authorities' commitment to implementing its advice. At the same time, the country authorities have their own conjectures about staff's advice. As previously noted, such conjectures can be determined by a number of factors, including working relationships with IMF staff, the implementation of its previous recommendations, and a cross-country comparative analysis of staff's advice. As noted by Bhattacharya et al. (1998), conjectures can also be based on knowledge about the incentives and potential punishments facing the other party and the past behavior of the latter. Given the characteristics of this model, there is no need for conjectures to be either time-invariant or rational. Let $b_{S}($.$) and b_{C}($.$) denote the conjecture$ functions of IMF staff and the country authorities.

Since IMF staff moves first by providing its advice during the stage of program design and negotiation, it ignores whether or not the program country authorities will implement its advice. However, it knows that the authorities will observe its action and adjust accordingly their conjectures about its advice. Therefore, IMF staff will take this knowledge into account by making its conjectures about the authorities' actions conditional on its own action. In contrast, the authorities' conjectures will only depend on IMF staff's actions. Hence, in what follows, $b_{S}\left(a_{C} \mid a_{S}\right)$ and $b_{C}\left(a_{S}\right)$ denote respectively the conjecture functions of IMF staff and the authorities.

For the IMF and its staff, the probability of obtaining outcome $x+\varepsilon_{S}$ given $a_{S}$ and $b_{S}\left(. \mid a_{S}\right)$ is

$\operatorname{Pr}$

$$
\left(\theta=x+\varepsilon_{S} \mid a_{S}, b_{S}\left(a_{C}\right)\right)=\sum_{a_{C} \in A_{C}} F\left(x+\varepsilon_{S} ; a_{S}, a_{C}\right) b_{S}\left(a_{C} \mid a_{S}\right)
$$

For the program country and its authorities, the probability distribution of outcome $x+\varepsilon_{C}$ given $a_{S}$ and $a_{C}$ is

$$
\operatorname{Pr}\left(\theta=x+\varepsilon_{C} \mid a_{S}, a_{C}\right)=F\left(x+\varepsilon_{S} ; a_{S}, a_{C}\right)
$$

Let $T_{i, j}$ denote the level of trust that a party $i$ has in the other party $j$, that is the extent to which $i$ believes that $j$ will take actions that have positive consequences for $i$. Basically, $T_{i, j}$ is the probability of obtaining a favorable outcome for party $i$ and it is calculated by summing the probability of obtaining outcome $x+\varepsilon_{i}$ over the set of outcomes $\Omega_{i}$ which party $i$ considers as positive for itself. In order to determine the level of trust that each party has in another, it is useful to take into account how each party behaves. Two alternative assumptions are made in what follows: (1) IMF staff and the program country authorities maximize the probability of favorable outcomes and (2) both parties are expected utility maximizers. 
Assumption 1: IMF staff and the authorities maximize the probability of favorable outcomes

The probability of obtaining an outcome favorable to the IMF and its staff, given $a_{\mathrm{s}}$ and $b_{S}\left(. \mid a_{S}\right)$ is

$\operatorname{Pr} \sum_{x+\varepsilon_{S} \in \Omega_{S}}\left(\theta=x+\varepsilon_{S} \mid a_{S}, b_{S}\left(. \mid a_{C}\right)\right)=\sum_{x+\varepsilon_{S} \in \Omega_{S}} \sum_{a_{C} \in A_{C}} F\left(x+\varepsilon_{S} ; a_{S}, a_{C}\right) b_{S}\left(a_{C} \mid a_{S}\right)$.

Hence, the level of trust that IMF staff has in country authorities is

$$
T_{S, C}=\operatorname{Pr}\left(U_{S}>0\right)=\max _{a_{S} \in A_{S}} \sum_{x+\varepsilon_{S} \in \Omega_{S}} \sum_{a_{C} \in A_{C}} F\left(x+\varepsilon_{S} ; a_{S}, a_{C}\right) b_{S}\left(a_{C} \mid a_{S}\right) .
$$

Analogously, the probability of obtaining an outcome favorable to the program country and its authorities, given $a_{S}$ and $a_{C}$ is

$\operatorname{Pr}$

$$
\sum_{x+\varepsilon_{C} \in \Omega_{C}}\left(\theta=x+\varepsilon_{C} \mid a_{S}, a_{C}\right)=\sum_{x+\varepsilon_{C} \in \Omega_{C}} F\left(x+\varepsilon_{C} ; a_{S}, a_{C}\right) .
$$

Hence, the level of trust that country authorities have in IMF staff is

$$
T_{C, S}=\operatorname{Pr}\left(U_{C}>0\right)=\sum_{a_{S} \in A_{S}}\left(\max _{a_{C} \in A_{C}} \sum_{x+\varepsilon_{C} \in \Omega_{C}} F\left(x+\varepsilon_{C} ; a_{S}, a_{C}\right)\right) b_{C}\left(a_{S}\right) .
$$

\section{Assumption 2: IMF staff and the authorities maximize their expected utility}

Given $a_{S}, a_{C}$, and $b_{S}\left(. \mid a_{S}\right)$, the expected utility to IMF staff and the program country authorities are respectively

$$
\left.E U_{S} a_{S}, c_{S}\left(. \mid a_{S}\right)\right)=\sum_{x+\varepsilon_{S}} \sum_{a_{C}} U_{S}\left(x+\varepsilon_{S}\right) F\left(x+\varepsilon_{S} ; a_{S}, a_{C}\right) b_{S}\left(a_{C} \mid a_{S}\right)
$$

and

$$
E U_{C}\left(a_{S}, a_{C}\right)=\sum_{x+\varepsilon_{C}} U_{C}\left(x_{C}\right) F\left(x+\varepsilon_{C} ; a_{S}, a_{C}\right) .
$$

If $a_{s}^{*}$ is the unique action that IMF staff can take to maximize its expected utility (or expected income), then the level of trust that staff has in the program country, $T_{S, C}$, is the probability of obtaining a favorable outcome for the IMF. That is

$$
T_{S, C}=\sum_{x+\varepsilon_{S} \in \Omega_{S}} \sum_{a_{C} \in A_{C}} F\left(x+\varepsilon_{S} ; a_{S}^{*}, a_{C}\right) b_{S}\left(a_{C} \mid a_{S}^{*}\right) .
$$


Similarly, if $a_{C}^{*}$ is the unique action that the country authorities can take to maximize their expected utility, then the level of trust that they have in IMF staff before the latter provides its advice, $T_{C, S}$, is the probability of obtaining a favorable outcome for the program country. That is

$$
T_{C, S}=\sum_{x+\varepsilon_{C} \in \Omega_{C}} \sum_{a_{S} \in A_{S}} F\left(x+\varepsilon_{C} ; a_{S}, a_{C}^{*}\left(a_{S}\right)\right) b_{C}\left(a_{S}\right)
$$

If a party can take several expected utility maximizing actions, then its level of trust in the other party is the highest probability of a favorable outcome among all of these actions.

It is noteworthy that the level of trust estimated above is that each party has in the other before the first mover (IMF staff) takes action. Once staff moves, trust loses its significance and becomes pure predictability. For a combination of given actions taken by the two parties, the concept of trust calculated above gives then an estimation of the non deterministic relationship between actions and outcomes. The level of trust obtained from Equation (6), (8), (11), and (12) is comprised between 0 (complete distrust) and 1 (complete trust). It tends to be in the neighborhood of these extreme values in case of so-called blind trust and distrust which are predispositions to assign these values and maintain them unconditionally regardless of the available evidence.

Even though the modeling approach used in this paper uses a concept of "a priori outcome" trust, it gives some useful indications about how subsequent developments during the different stages of the game feed back into the level of trust between the two parties. This suggests that the level of trust between the two parties, particularly the authorities' trust in staff, is not static and thus must not be taken as granted. Taking trust as granted may lead staff to form unwarranted expectations of favorable program outcomes and provide fewer incentives for it to make additional efforts that may potentially be needed to secure such outcomes in a low trust environment. It is therefore important for each party to recognize that it must earn the other party's trust and work persistently to that effect. Such an attitude may be critical for successful long-term IMF engagement in program countries.

\section{CONCLUSIONS AND POLICY IMPLiCATIONS FOR THE IMF}

In light of the previous analysis and the model developed in this paper, this concluding section identifies policy actions that the IMF can take to secure the potential positive impact of trust on program success. It then draws the attention of the reader on trust-building initiatives that the institution can consider. ${ }^{14}$ Finally, it suggests a few issues for further research.

\footnotetext{
${ }^{14}$ The paper also provides some indications about how country authorities can build trust and secure the benefits of trusting relationships with IMF staff. But, for practicality purposes, only initiatives that can be undertaken by the IMF to this end are discussed hereafter.
} 


\section{A. Trust and Program Success}

In light of the issues addressed and the model developed in this paper, there are strong indications that trust matters for the success of IMF-supported programs. At the outset, a member's decision to embark on a program relationship with the IMF is by itself, in many instances, a reflection of the high level of trust that it has in the institution. If its level of trust in the institution was too low, the member country would, most likely, not request an IMFsupported program. Nevertheless, there may be, indeed, other considerations that can lead a member country to request an IMF arrangement despite a low level of trust in the IMF. Among these considerations, many involve some sense of urgency, including, but not limited to, pressing needs for IMF resources, signaling, and involvement in crisis resolution.

Once a program relationship is effective between the IMF and a member country, then a number of trust-impacting issues are likely to emerge in various ways at each stage of the design, negotiation, and implementation of an IMF-supported program. As suggested by the model developed in this paper, such issues can impact on the level of trust between IMF staff and the authorities by affecting the likelihood of obtaining favorable outcomes for each party and the conjectures about each other's actions. In turn, it is shown that trust has, in many ways, positive implications for the potential success of this relationship.

In order to fully secure the positive impact of trust on program success, a number of steps can be taken. First, given that trust may contribute to program success by ensuring sounder program design, a cautious approach is warranted on the part of IMF staff when setting conditionality and making macroeconomic projections. ${ }^{15}$ On the one hand, given its inherent tension with ownership, conditionality may induce distrust, especially if deemed unwarranted or flawed by the country's authorities. Accordingly, efforts aimed at streamlining it may prove useful. In parallel, ensuring an active involvement of the program country in the design of conditionality may be a good recipe for reducing its potential, adverse impact on trust. On the other hand, when IMF projections deviate from actual outcomes, there is always a risk of backlash on the level of trust that the institution enjoys, regardless of the cause of the deviation. In order to reduce this risk, more focus should be put on the realism of program assumptions and country's authorities should actively and systematically contribute to the process of making the projections.

Second, to the extent that trust can be a key determinant of successful IMF engagement through its positive role in an efficient program negotiation, there is merit in taking actions that enable it to fulfill this role. To this end, initiatives aimed at strengthening staff's knowledge of both IMF procedures and specific circumstances of the program country as well as individual and interpersonal skills of mission team members can be valuable.

Third, since trust increases the likelihood of program success by facilitating program implementation, a worthy endeavor by the IMF is to identify and address country-specific

\footnotetext{
${ }^{15}$ While country authorities are primarily responsible for program design, the IMF is accountable for its quality and conditionality. Issues of IMF accountability have trust-building implications that are discussed in the next section.
} 
factors that are likely to impact on the authorities' level of trust in staff and influence their propensity to implement staff's advice. As previously discussed, such factors can include the quality of staff's advice; the outcomes, consequences, and costs of its implementation; and the relationship between the quality and implementation outcome of staff's advice.

Finally, the numerous risks to program success related to a low level of trust between IMF staff and the authorities must be addressed. Distrust may encourage strategic or vindictive behavior on the part of at least one of the two parties along with potentially adverse implications on the outcome of program engagement. Therefore, there are many reasons to believe the IMF must always work on maintaining trusting relations with its program countries. In fact, this happens to be one of perceived roles of the IMF as a trusted advisor to country authorities. Nevertheless, such an endeavor must be undertaken in the context of prudent IMF policies aimed at addressing trust-related vulnerabilities. In this regard, IMF's safeguard policies can play an important role.

\section{B. Trust Building in a Program Context}

Since trust is shown to have major implications for program success, a worthy endeavor is to examine the process of building and losing trust in a program context. The previous sections show that trusting relationships between a program country's authorities and IMF staff may be heavily influenced by a number of factors, including the perception of each other's individual skills and characteristics, the actual and expected outcomes of past and ongoing IMF arrangements, the perceived quality, origin, and timing of staff's advice, and the outcome of IMF involvement in other countries.

In light of these determinants of trust, there are a number of initiatives that the IMF can undertake in order to build trust in program countries. First, a more systematic dissemination of program success stories may help influence positively trust to the extent that the authorities' conjectures about the quality and effectiveness of the advice provided by staff, and thus the IMF, appear to be built on a cross-country comparison of staff's advice. At the same time, extracting more methodically the lessons learnt from program failures and feeding them systematically into active IMF arrangements could help increase the probability of program success. In this endeavor, the IMF's Independent Evaluation Office (IEO) could be a very useful tool for strengthening the institution's learning culture and ongoing efforts to follow-up more forcefully with its Board-endorsed recommendations are steps in the right direction.

Second, another trust-building initiative can consist in promoting shared meanings and better clarifying underlying program understandings with the program country. Asymmetry of information between both parties may lead to different interpretations of the content of the memorandum of understanding on economic and financial policies and other concepts critical to program relationship. In turn, such differences of interpretation are likely to backlash on trust in the event of unfavorable outcomes of program engagement. Therefore, the promotion of shared meanings and clarification of disclosed and undisclosed understandings, whether oral and written, can help safeguard trust from undue influence by strengthening the accountability of both the IMF and the program country for the outcomes of program involvement. Indeed, it goes without saying that shared meanings are best achieved through cooperation over 
domination and negotiation over imposition. And in this process, IMF Management and the offices of both the Executive Director for the program country and the Resident Representative can play a key role in this process of ensuring shared meanings and clarifying understandings and, more generally, in nurturing trusting relations between the two parties. ${ }^{16}$

Third, making a set of alternative policy options, including homegrown ones, systematically available to the authorities can increase their level of trust by allowing them to select options that are most likely to lead to favorable outcomes from the perspective of the program country. Under these circumstances, the selection of preferred options for the IMF can be encouraged by a mechanism design with appropriate incentives for the program country to implement the desired policy actions. Similarly, the provision of adequate policy space for homegrown options can help build trust through stronger ownership.

Fourth, increased transparency of IMF's interactions with its program countries can help build trust. On the one hand, it reduces distrust induced by the perception of weak IMF accountability held by some authorities and critics. Whether or not this perception is adequate is beyond the scope of this paper. However, in situations where the authorities themselves perceive that staff is unaccountable, steps taken by the IMF to increase transparency may need to be coupled with complementary actions aimed at strengthening accountability if this perception is deemed adequate, and at demonstrating, otherwise, how staff is held accountable for its advice. In either case, the IEO has certainly an important role to play in strengthening the accountability framework of the IMF. On the other hand, increased transparency can also affect positively conjectures about the work of the IMF and the quality of its advice, thereby increasing the level of trust that the institution enjoys. In particular, improved transparency about the rationale for both IMF-supported programs and staff's advice can be of critical importance. Indeed, it appears that many outsiders, including some country authorities and critics of the IMF, do not always have full access to information about the underpinnings of IMF's advice and arrangements, which tends to undermine their a priori trust in the institution. Clearly, the potential sensitiveness of information provided by country authorities combined with the IMF role as a confidential advisor may considerably limit the institution's ability to fully disclose, in a systematic manner, all facets of its interactions with program countries. Subject to these constraints, the IMF would greatly benefit from improved transparency, particularly about the rationale for both its arrangements and advice. In this regard, the IMF's external relations department can play a critical role in collaboration area departments.

Finally, adequate trusting relationships between the IMF and a program country are likely to be self-sustainable. It is likely that trust begets more trust in the absence of a trust-destroying behavior by one party. This hysteresic property of trust underscores the merits of nurturing trust when the quality of the policy dialogue between the IMF and a program country is deemed good. Given that trust has positive implications for the outcome of program engagement, a destruction of trust by any of the two parties can be expected to generate negative effects on the

\footnotetext{
${ }^{16}$ For instance, based on the experience of the IMF in one of its member countries, the Independent Evaluation Office of the IMF elaborates on how the Resident Representative can promote a mutually beneficial dialogue with the authorities by contributing to an atmosphere of trust (see IEO, 2004).
} 
likelihood of program success by causing inadequate program design and implementation and increasing transaction costs associated with program relationships. While it usually takes time to build trust between two parties, it may take little to damage it. In a program context, trust in staff can be undermined for various reasons. The model presented in this paper suggests that staff's policy advice can undermine trust in the IMF and its staff if deemed ill-designed by the authorities. ${ }^{17}$ Through the authorities' conjectures about staff's advice, trust in the IMF and its staff can also be adversely affected by a number of other factors, including overly prescriptive conditionality, high turnover in the IMF's country team, and perceptions that staff's advice is biased toward unappreciated demands formulated by nongovernmental and external stakeholders. In this regard, frequent reviews of conditionality and internal personnel policies can help detect any potential inadequacies that need to be addressed.

\section{ISSUES FOR FURTHER RESEARCH}

Since the literature on trust in the context of IMF's relations with its members is virtually nonexistent, there are obviously plentiful research avenues that remain to be explored. In a program context, the model developed in this paper is a useful starting point. However, given that the strength of trust between IMF staff and country authorities is most likely to evolve during successive programs and reviews, the extension of the scope of the model to account explicitly for the trust impact of program monitoring and past IMF arrangements may be a useful endeavor that can help better capture the dynamic nature of trust. There are reasons to believe that issues of trust in the stage of program monitoring have in some extent many similarities with those emerging during program design and negotiation.

As previously discussed, this paper does not address trust-related issues that emerge prevalently in the context of other IMF's activities such as surveillance and technical assistance. It is likely that such issues have implications on the effectiveness of these activities that differ from those considered in this paper. In order to investigate these issues, the study of trust between the IMF and member countries and its impact on the effectiveness of IMF's work could be of great interest outside a program context.

Empirical studies have been conducted to determine how large organizations can benefit from trust among their employees. Similar initiatives may prove very productive in the context of the IMF. In this regard, it could be rewarding to explore how intra-organizational trust matters for the effectiveness of IMF's activities. Since trusting relationships between the Executive Board and Management and staff are clearly critical for the efficient functioning of the institution, further investigation of intra-organizational trust can help better elucidate how such relationships can be nurtured and strengthened. Indeed, a few studies have analyzed the relationship between the Executive Board, Management and staff, but they have done so

\footnotetext{
${ }^{17}$ Similarly, it is reasonable to suppose that trust in country authorities can be damaged as a result of misreporting cases, accumulation of arrears to the IMF, and chronic and politically motivated failures to implement critical program conditions.
} 
exclusively from an IMF governance viewpoint, with no specific focus on trust issues. ${ }^{18}$ And even if the focus is on IMF governance, it may be worth assessing its impact on members' trust in the institution.

${ }^{18}$ More recently, Santor (2006) examine IMF governance and argues that principal-agent problems may exist between the Managing Director and the Executive Board. 


\section{REFERENCES}

Alesina, Alberto and Eliana La Ferrara (2000), "The Determinants of Trust," NBER Working Paper No. 7621.

Arrow, Kenneth (1972), "Gifts and Exchanges," Philosophy and Public Affairs, Vol.1, No. 4, pp. 343-362.

Arrow, Kenneth (1974), The Limits of Organization, W. W. Norton \& Company Inc., New York.

Bhattacharya, Devinney, and Pillutla (1998), "A Formal Model of Trust Based on Outcomes," The Academy of Management Review, Vol.23, No.3. (July 1998), pp. 459-472.

Bohnet, Iris and Kessely Hong (2004), "Status and Distrust: The Relevance of Inequality and Betrayal Aversion," Harvard PON Working Paper.

Carter, Jonathan and Ali A. Ghorbani (2002), "Towards a Formalization of Trust," University of New Brunswick.

Chami, Ralph and Connel Fullenkamp (2002), "Trust as a Means of Improving Corporate Governance and Efficiency”, IMF Working Paper WP/02/33, Washington, February 2002.

Dasgupta, Partha (1988), "Trust as a Commodity", in Gambetta, Diego (Ed.) Trust: Making and Breaking Cooperative Relations, University of Oxford, pp. 49-72.

Fisher, Roger (1991), "Beyond Yes”, Harvard Program on Negotiation, Cambridge, Massachusetts.

Gambetta, Diego (2000), “Can We Trust Trust?” In Gambetta, Diego (Ed.) Trust: Making and Breaking Cooperative Relations, University of Oxford, Chapter 13, pp. 213-237.

Hardy, Cynthia, Nelson Phillips, and Tom Lawrence (1998), "Distinguishing Trust and Power in Interorganizational Relations. Forms and Facades of Trust," In: Christel Lane and Reinhard Bachmann (Eds.), Trust within and between Organizations. Conceptual Issues and Empirical Applications, New York, p. 64-87.

Independent Evaluation Office (2004), "Evaluation of the IMF's Role in Poverty Reduction Strategy Papers and the Poverty Reduction and Growth Facility", Washington, July 2004.

International Monetary Fund (2004), "Policy Formulation, Analytical Frameworks, and Program Design," Washington, November 2004.

International Monetary Fund (2004), "Fund-Supported Programs - Objectives and Outcomes," Washington, November 2004. 
International Monetary Fund (2006), "Review of Ex Post Assessments and Issues Relating to the Policy on Longer-Term Program Engagement," Washington, March 2006.

La Porta, Rafael; Florencio Lopez-de-Silanes; Andrei Shleifer; and Robert Vishny (1997), "Trust in Large Organizations," The American Economic Review, Vol. 87, No. 2, Papers and Proceedings of the Hundred and Fourth Annual Meeting of the American Economic Association, pp.333-338.

Lewicki, Roy J. and Barbara Benedict Bunker (1995) "Trust in Relationships: A Model of Development and Decline." In Conflict, Cooperation and Justice: Essays Inspired by the Work of Morton Deutsch, Eds. Barbara Benedict Bunker and Jeffery Z. Rubin. San Francisco: JosseyBass, pp 133-174.

Lewis, J. David and Andrew Weigert (1985), "Trust as a Social Reality," Social Forces, Vol. 63, No. 4, pp. 967-85.

Luhmann, Niklas (1979), Trust and Power, New York: Wiley.

Luhmann, Niklas (2000), "Familiarity, Confidence, Trust: Problems and Alternatives," in Gambetta, Diego (ed.) Trust: Making and Breaking Cooperative Relations, University of Oxford, Chapter 13, pp. 213-237.

Mirakhor, Abbas (2005), "Globalization and Islamic Finance", Paper Presented in the Sixth International Conference on Islamic Economics and Finance, Jakarta, Indonesia, November $21-24,2005$.

Ring, Peter S., and Andrew H. Van De Ven (1992), "Structuring Cooperative Relationships Between Organizations," Strategic Management Journal, Vol. 13, pp. 483-498.

Sabel, Charles F. (1993), "Studied Trust: Building New Forms of Co-operation in a Volatile Economy," In Richard Swedberg (Eds.), Explorations in Economic Sociology, New York Russel, pp. 104-44.

Santor, Eric (2006), "Governance and the IMF: Does the Fund Follow Corporate Best Practice?” Bank of Canada Working Paper 2006-32.

Van de Ven, Andrew H. and Gordon Walker (1984), "The Dynamics of Interorganizational Coordination," Administrative Science Quarterly, Vol. 29, pp. 598-621.

Zaheer, Akbar; McEvily, Bill; and Vincenzo Perrone (1998), "Does Trust Matter? Exploring the Effects on Interorganizational and Interpersonal Trust on Performance," Organization Science, Vol.9, No. 2, pp. 141-159.

Zucker, L. G. (1986), "Production of Trust: Institutional Sources of Economic Structure", In B.M. Staw and L.L. Cummings (Eds.), Research in Organizational Behavior, pp. 53-112. 